\title{
The Many Faces of Persistent Stapedial Artery: CT Findings and Embryologic Explanations
}

\author{
(D) Z.J. LoVerde, (DD.P. Shlapak, (D).C. Benson, (D) M.L. Carlson, and (D).I. Lane
}

\begin{abstract}
SUMMARY: Persistent stapedial artery is a vascular anomaly with both clinical and surgical implications. Because of its scarcity, however, it remains underrecognized on imaging. Presented here is a series of 10 cases, demonstrating characteristic CT findings associated with this vascular anomaly and its most common pathognomonic imaging signs. The variable morphologic configurations and their corresponding embryologic underpinnings are described. Clinical and surgical implications of this rare anomaly are discussed.
\end{abstract}

ABBREVIATION: PSA = persistent stapedial artery; MMA = middle meningeal artery; CCA = common carotid artery; CTC = caroticotympanic canaliculus; $\mathrm{ITC}=$ inferior tympanic canaliculus; $\mathrm{CHL}=$ conductive hearing loss; $\mathrm{ECA}=$ external carotid artery; ICA $=$ internal carotid artery; CTA = caroticotympanic artery; ITA = inferior tympanic artery; FNC = facial nerve canal

$\mathbf{P}$ ersistent stapedial artery (PSA) is a rare vascular anomaly, with an estimated prevalence of $0.02 \%-0.5 \%{ }^{1,2}$ Although its existence has been well documented dating back to Hyrtl in $1836,{ }^{3}$ its characteristics on advanced imaging are sparse. Classic studies have focused mainly on surgical encounters, ${ }^{4-6}$ histologic dissection, ${ }^{2,7-10}$ tomography, ${ }^{11}$ or angiography. ${ }^{12-14}$ More recent elucidations on $\mathrm{CT}^{13-17}$ are limited by small sample size, few multiplanar reconstructions, and relatively cursory discussions of its morphologic variability. Several cases have been described using MR angiography. ${ }^{18,19}$ The purpose of this case series is to provide a clear, image-rich resource on CT appearance of a PSA and a focused embryologic framework to facilitate understanding its variable configurations.

\section{METHODS}

A systematic search of a single-center registry of radiologic reports was performed to identify high-resolution temporal bone CT examinations between January 1, 2005, and March 10, 2020, using the term "persistent stapedial artery." Eleven patients were reviewed by a single attending neuroradiologist with more than 20 years of experience and a Certificate of Added Qualification in neuroradiology. All examinations were performed on multidetector scanners from a single vendor (Siemens) ranging from 64- to 192-section platforms. Standard reconstructions in axial, coronal, and Pöschl

Received April 25, 2020; accepted after revision August 11.

From the Departments of Radiology (Z.J.L., D.P.S., J.C.B., J.I.L.) and OtolaryngologyHead and Neck Surgery (M.L.C.), Mayo Clinic, Rochester, Minnesota. INSTITUTIONAL REVIEW BOARD APPROVAL: 20-002533.

Please address correspondence to Darya P. Shlapak, MD, MBA, Department of Radiology, Mayo Clinic, 200 1st St. SW, Rochester, MN 55905; e-mail: shlapak.darya@mayo.edu

http://dx.doi.org/10.3174/ajnr.A6851 planes were reviewed on a PACS workstation (Visage Imaging) in conjunction with multiplanar reformations. Of these cases, 2 were excluded because they demonstrated an absent foramen spinosum but no additional findings of a PSA, with presumed ophthalmic origin of the middle meningeal artery (MMA). Hence, 9 patients were included in the final cohort. Characteristic imaging findings and representative images were described.

\section{RESULTS}

\section{Radiologic Findings}

Of the 9 included patients (10 affected ears), 6 PSAs were leftsided and 4 right-sided, including 1 bilateral. All had an absent ipsilateral foramen spinosum and a visible vessel traversing the cochlear promontory. Seven had an associated enlarged caroticotympanic canaliculus (CTC); the other 3 had an enlarged inferior tympanic canaliculus (ITC). Six had an associated duplicated fallopian canal. An observable vessel within the obturator foramen of the stapes was noted in 8 cases; in the remaining 2, 1 vessel traversed anterior to a dysplastic stapedial crus, and the other was obscured by granulation tissue (confirmed at surgery).

\section{Clinical Data}

Three patients had underlying congenital anomalies, including ipsilateral congenital cholesteatoma, ipsilateral congenital aerodigestive venolymphatic malformation, and chromosome $3 \mathrm{q}$ duplication or trisomy. Four patients had conductive hearing loss (CHL) documented by audiogram, with air-bone gaps ranging from 20-60 dB, 1 of which was alternatively attributable to congenital cholesteatoma. The single patient with bilateral PSAs (right PSA confirmed at surgery) had bilateral $\mathrm{CHL}$, right greater than left, and remote left 

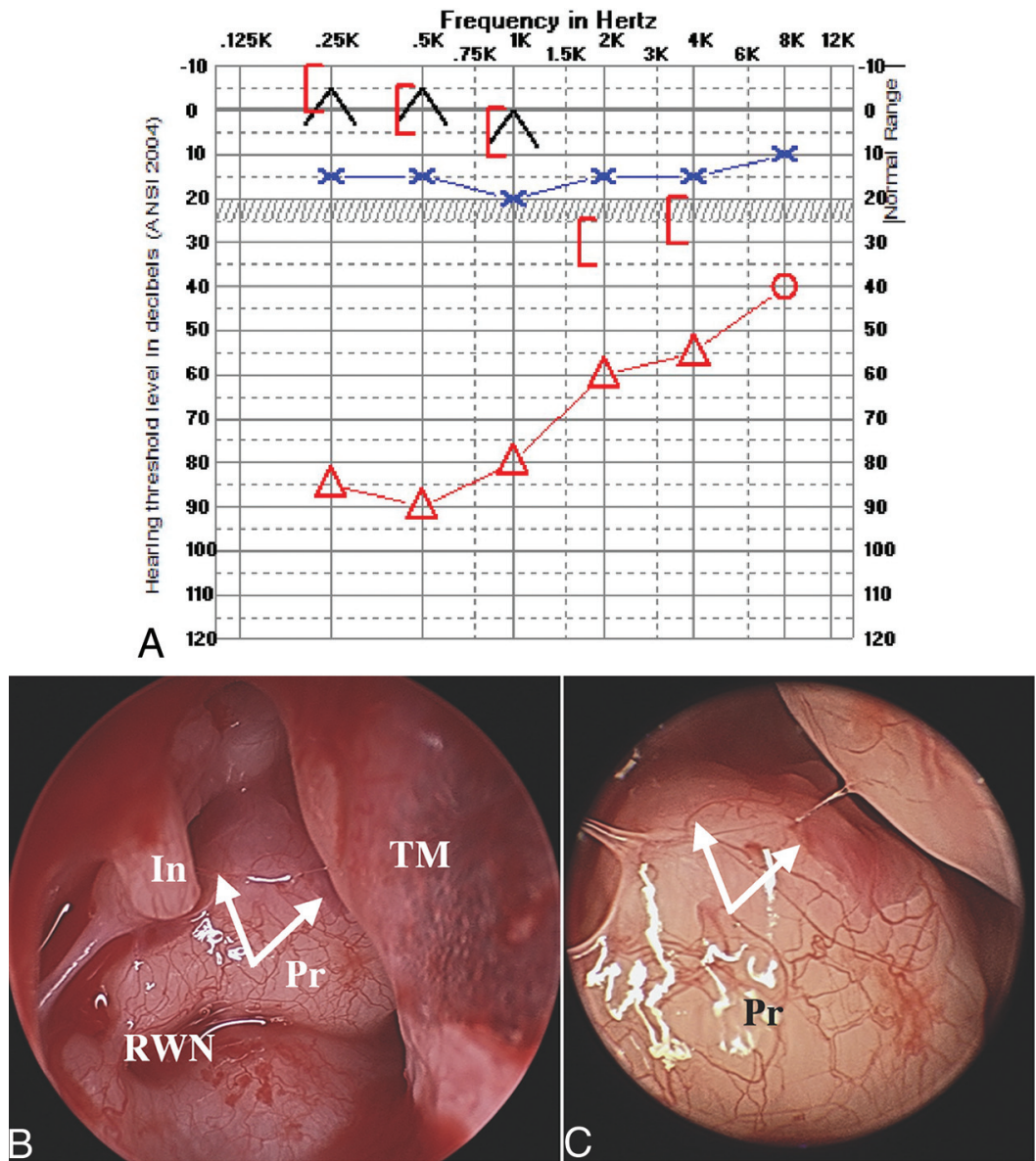

FIG 1. A, Preoperative audiogram demonstrates a right-sided near-maximal $\mathrm{CHL}$ and normal hearing thresholds in the left ear. $B$ and $C$, Right middle ear intraoperative endoscopy demonstrates right PSA (white arrows) coursing over the surface of the cochlear promontory. Notably, the inferior half of the artery was encased within promontory bone; however, the superior aspect was dehiscent and easily visible during surgery. In this patient, the artery and facial nerve were pulsatile. In = incus; $\operatorname{Pr}=$ promontory of cochlea; $\mathrm{RWN}=$ round window niche; $\mathrm{TM}=$ tympanic membrane. middle ear surgery. One patient with CHL reported concomitant pulsatile tinnitus. Four PSAs were considered purely incidental without attributable symptoms. Two patients had normal audiograms, 1 had a coincidental sensorineural deficit, and 2 did not have audiograms performed. Three PSA cases were confirmed by exploratory middle ear surgery. Of these, 1 PSA was intentionally divided followed by ossicular chain reconstruction in a patient with history of congenital cholesteatoma. Postoperatively, this patient experienced significant improvement in $\mathrm{CHL}$ and normal facial nerve function. The other 2 surgeries were aborted after encounter of the PSA, 1 because of bleeding, ultimately controlled, and the other because of concern for potential facial nerve injury with artery division, given prominent pulsations within the facial nerve substance. Fig 1 demonstrates a preoperative audiogram $(A)$ and intraoperative endoscopic photographs $(B$ and $C$ ) for 1 of the patients. The main imaging and clinical findings are summarized in the Table.

\section{DISCUSSION \\ Embryologic Origins}

Understanding the embryology and typical regression pattern of the stapedial artery helps to explain its intratemporal course. Much of our fundamental

Patient characteristics and prevalence of associated persistent stapedial artery findings

\begin{tabular}{|c|c|c|c|c|c|c|c|c|c|c|}
\hline Case & Side & Associated Anomalies & $\mathrm{CHL}$ & $\begin{array}{l}\text { Duplicated } \\
\text { FNC }\end{array}$ & $\begin{array}{l}\text { Fr } \\
\text { Spn }\end{array}$ & $\begin{array}{l}\text { Coch } \\
\text { Prom } \\
\text { Vessel }\end{array}$ & $\begin{array}{l}\text { Large } \\
\text { CTC }\end{array}$ & $\begin{array}{l}\text { Large } \\
\text { ITC }\end{array}$ & $\begin{array}{l}\text { Stapes } \\
\text { Obturator } \\
\text { Artery }\end{array}$ & $\begin{array}{c}\text { Surgical } \\
\text { Confirmation } \\
\end{array}$ \\
\hline 1 & $\mathrm{~L}$ & None & + & + & - & + & + & - & + & - \\
\hline 2 & $L$ & $\begin{array}{l}\text { Ipsilateral congenital cholesteatoma } \\
\text { and dysplastic anterior stapedial crus }\end{array}$ & + & - & - & + & + & - & + & + \\
\hline 3 & $\mathrm{~L}$ & None & $\mathrm{N} / \mathrm{A}$ & + & - & + & - & + & + & - \\
\hline 4 & $\mathrm{~L}$ & None & - & - & - & + & - & + & + & - \\
\hline 5 & $\mathrm{R}$ & $\begin{array}{l}\text { Ipsilateral congenital aerodigestive } \\
\text { venolymphatic malformation and } \\
\text { dysplastic stapes }\end{array}$ & + & - & - & + & + & - & $-^{c}$ & + \\
\hline 6 & $\mathrm{R}$ & $\begin{array}{l}\text { Chromosome } 3 q \text { duplication or } \\
\text { trisomy }\end{array}$ & $\mathrm{N} / \mathrm{A}$ & + & - & + & + & - & + & - \\
\hline 7 & $\mathrm{R}$ & None & - & + & - & + & - & + & + & - \\
\hline 8 & $\mathrm{~L}$ & None & - & - & - & + & + & - & + & - \\
\hline $9^{a}$ & $\mathrm{R}$ & None & + & + & - & + & + & - & $-{ }^{d}$ & + \\
\hline $10^{a}$ & $\mathrm{~L}$ & None & $+^{b}$ & + & - & + & + & - & + & - \\
\hline
\end{tabular}

a \#9 and \#10: bilateral PSA; same patient.

$\mathrm{b} \# 10$ remote middle ear surgery, not otherwise specified.

c \#5 PSA anterior to the dysplastic crus.

${ }^{d}$ \#9 granulation tissue obscured artery.

Note:-Findings are marked as either present $(+)$ or absent $(-)$ in each patient. Coch Prom indicates cochlear promontory; FNC $=$ facial nerve canal; Fr Spn $=$ foramen spinosum; N/A = not applicable. 
understanding results from embryologic investigations performed by Congdon, ${ }^{20}$ later clarified by Padget ${ }^{21}$ and summarized by Altmann ${ }^{22}$ and Steffen ${ }^{23}$ in the early and mid-20th century.

Within the 6 embryonic pharyngeal arches, paired arterial arches course from the aortic sac to the ipsilateral of the paired descending dorsal aortas. The first and second arches give rise to the ventral pharyngeal artery, later to become the external carotid artery (ECA); the third arch artery becomes the proximal ICA; and the ventral third-fourth arch junction becomes the common carotid artery (Fig 2). The hyoid artery is the dorsal remnant of the second aortic arch and constitutes the stem of stapedial artery, around which the stapedial ring will form, giving rise to the characteristic obturator foramen of the stapes. ${ }^{10,24}$ Immediately beyond the stapes, the stapedial artery ramifies into an upper division, which has a dorsal branch to become the MMA, ventral branch to supply the orbit, and a lower (maxillomandibular) division with infraorbital and mandibular branches.

Later, an anastomotic branch develops between the maxillomandibular division of the stapedial artery and plexiform branches of the distal ventral pharyngeal artery, connecting the ICA and ECA systems. This anastomosis will become the internal maxillary artery and results in an annexation of stapedial territorial supply by the ECA, allowing for normal involution of the stapedial and hyoid arteries (Fig 3A).

\section{Anatomic Variants}

The anatomic variations are best categorized proximally by their arterial origins and distally by their transmitting osseous foramina. In the most straightforward proximal arrangement, the PSA is supplied by an enlarged caroticotympanic artery (CTA), a remnant of the embryonic hyoid artery stem arising from the petrous ICA by way of the

FIG 2. Primitive aortic arches embryology. A, Paired 6 aortic arches course from the aortic sac to the ipsilateral descending dorsal aorta (right dorsal aorta is annotated). B, First and 2nd arches give rise to the ventral pharyngeal artery, later to become ECA; the 3rd arch becomes proximal ICA; and the ventral 3rd-4th arch junction becomes the common carotid artery. Used with permission of Mayo Foundation for Medical Education and Research, all rights reserved.

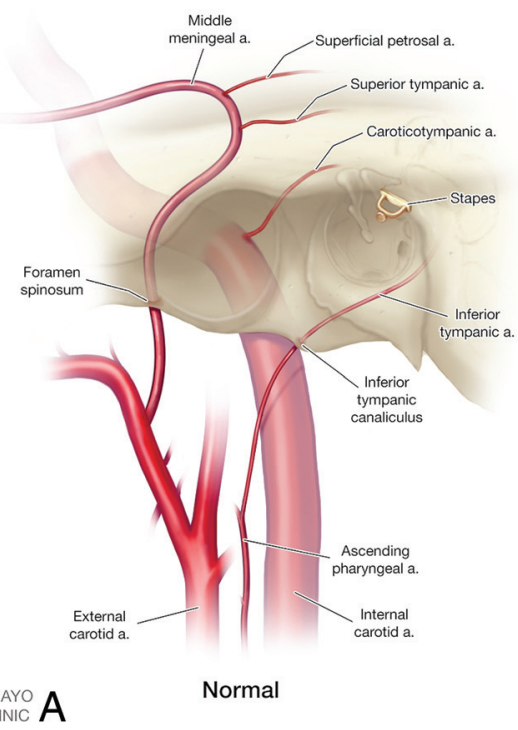

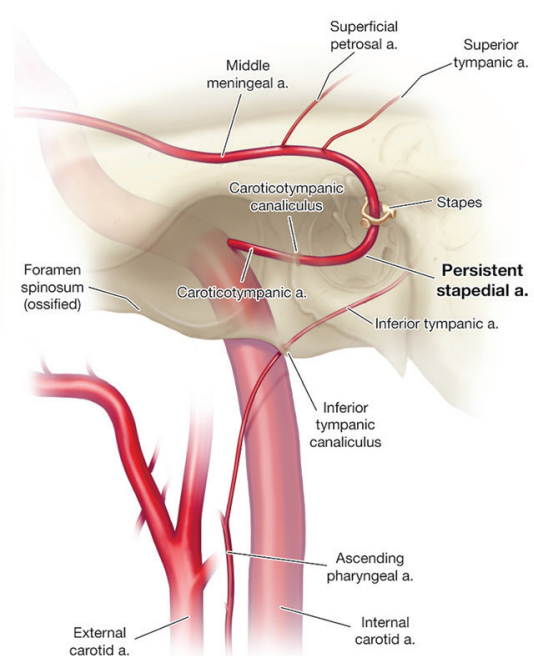

B

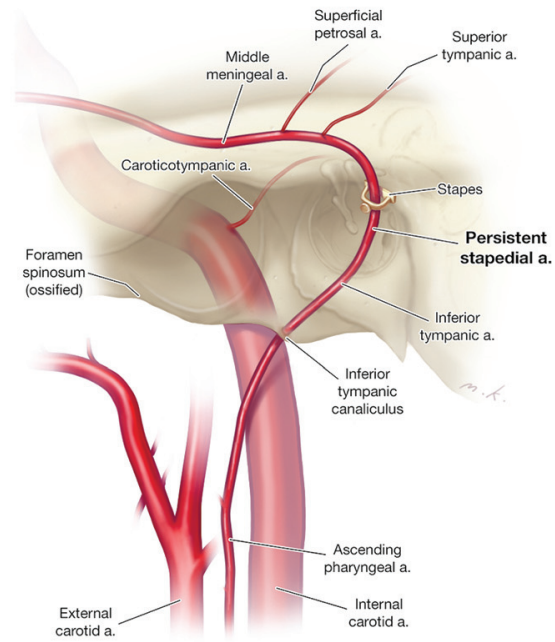

C

FIG 3. Normal carotid vascular anatomy $(A)$ and anatomic variants of persistent stapedial artery (PSA, $B$ and $C)$. $B$, PSA is supplied by an enlarged caroticotympanic artery, a remnant of the embryonic hyoid artery stem arising from the petrous ICA via caroticotympanic canaliculus; this anatomic variant is referred to as persistent hyoidostapedial artery. C, PSA is supplied by an enlarged inferior tympanic artery, a branch of the ascending pharyngeal artery, which travels through the inferior tympanic canaliculus into the middle ear, anastomosing with the embryonic hyoid artery; this anatomic variant is referred to as persistent pharyngostapedial artery. Used with permission of Mayo Foundation for Medical Education and Research, all rights reserved. 

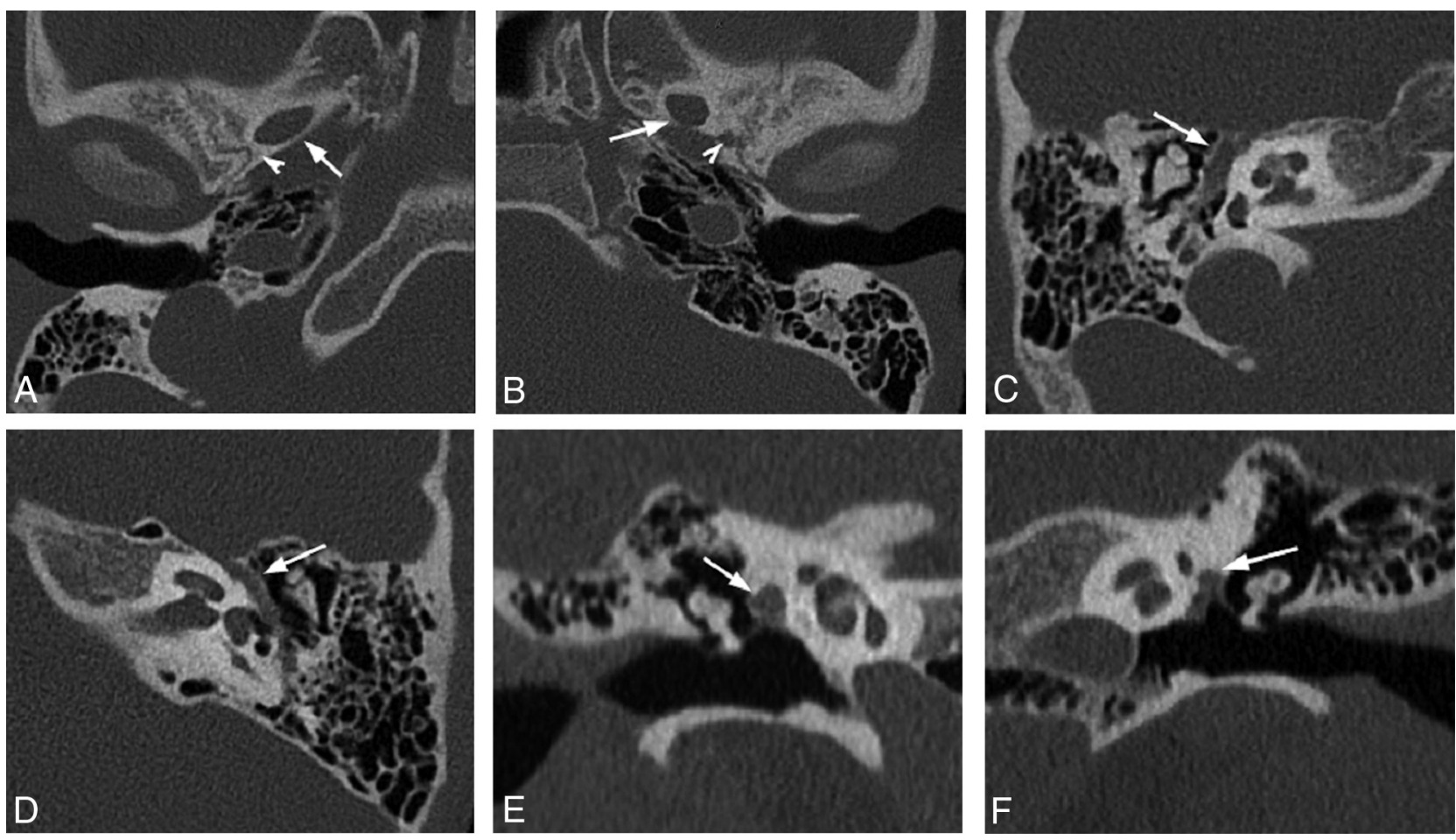

FIG 4. Nonspecific findings of PSA. Axial oblique CT reconstructions of right $(A)$ and left $(B)$ temporal bones in the same patient with the right PSA demonstrate normal foramen spinosum on the left and absent on the right at its expected location (arrowheads); note the normal foramen ovale on both sides (arrows). Axial $(C)$ and coronal $(E)$ oblique reconstructions of nonduplicated, enlarged tympanic segment of the right facial nerve canal (FNC). Nonduplicated FNC is enlarged to accommodate facial nerve and PSA (arrows). Compare with normal nonenlarged left FNC in similar planes, $D$ and $F$ (arrows).

CTC, referred to as a persistent hyoidostapedial artery (Fig 3B). The foramen spinosum is typically absent but may rarely persist if the PSA retains distribution to the maxillary artery through the MMA ("complete" hyoidostapedial artery). ${ }^{25}$ In normal development, the CTA typically completely involutes ${ }^{26,27}$ or anastomoses with the anterior tympanic and stylomastoid arteries.

Alternatively, the PSA may be supplied by an enlarged inferior tympanic artery (ITA), a branch of the ascending pharyngeal artery. The ITA travels through the ITC (Jacobson canal) into the middle ear, anastomosing, normally only transiently, with the embryonic hyoid artery. Because the ITA derives from the embryonic ventral pharyngeal artery, this has been referred to as a persistent pharyngostapedial artery (Fig 3C). ${ }^{18,28}$

An "aberrant" ICA results from involution or agenesis of the orthotopic distal cervical ICA. The detoured ICA represents an enlargement of both the ITA and CTA, with a resultant flow reversal in the CTA to supply the horizontal petrous ICA. When present in conjunction with a PSA, this has been termed an aberrant carotid stapedial artery. ${ }^{28}$ An exceedingly rare variation but present in the current series (case 4) involves enlargement of both the CTA and ITA supplying the PSA with preserved orthotopic cervical ICA, referred to as a pharyngohyostapedial artery. ${ }^{14,29}$

Distal variation is at the fallopian canal level, which may be duplicated or enlarged. In duplication, PSA enters the tympanic segment of the fallopian canal through an inferior dehiscence and then exits laterally into a separate bony canal just posterior to the cochleariform process. This discrepancy may be the result of embryonic exploitation of alternate vascular pathways involving 2 divisions of the petrous branch of the MMA, namely, the superior tympanic artery and superficial petrosal artery. The superior tympanic artery enters the temporal bone through the superior tympanic canaliculus near the facial hiatus, following the lesser petrosal nerve, and the superficial petrosal artery travels within the fallopian canal with the facial nerve. ${ }^{10,12,30}$ Depending on which of these 2 is involved, either a duplicated (superior tympanic) or an enlarged (superficial petrosal) facial canal may be seen. ${ }^{15}$ In both settings, PSA subsequently traverses the floor of the middle cranial fossa, dividing laterally to become the MMA and to anastomose medially with orbital vessels. ${ }^{23,31}$

Except for the "complete" hyoidostapedial artery variant, nearly all types of PSA typically have an absent ipsilateral foramen spinosum as did all cases in our series. In normal development, foramen spinosum forms around the maxillomandibular division of the stapedial artery near its anastomosis with the ventral pharyngeal artery. The absence or transience of this anastomosis in the setting of a PSA prevents foramen formation. Nevertheless, the absence of foramen spinosum is not specific to a PSA because it can also be associated with other variant origins of the MMA. ${ }^{32}$

\section{IMAGING SIGNS}

Classic PSA imaging features include absent foramen spinosum (Fig $4 A,-B$ ) and enlargement of the anterior portion of the tympanic segment of the facial nerve canal (Fig $4 C-F$ ), neither of which is specific. Herein, we describe the most common CT findings that provide direct evidence of a PSA, allowing radiologists to more confidently identify this rare anomaly. 

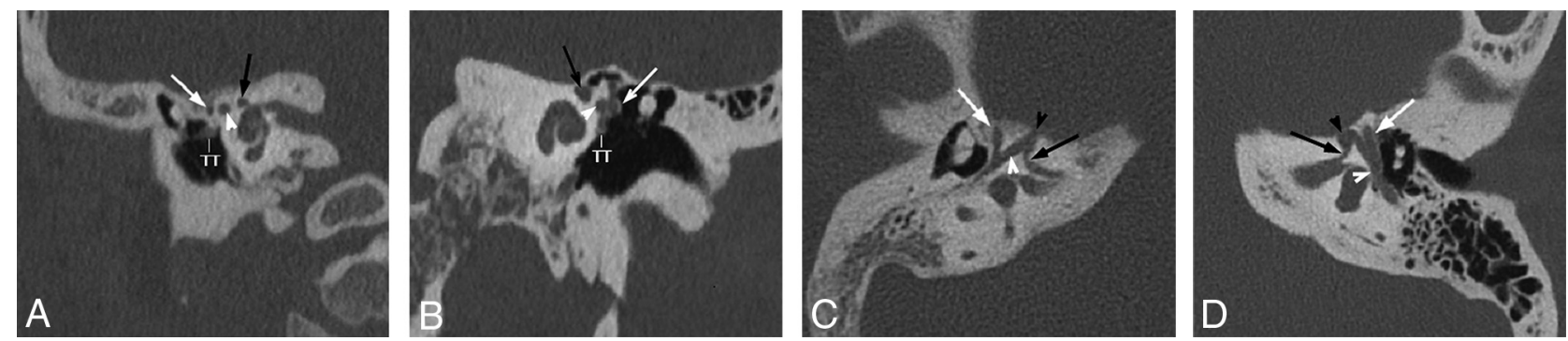

FIG 5. Right ear $(A)$ and left ear $(B)$ coronal $C T$ images from 2 patients demonstrate an additional lumen lateral to the tympanic facial canal (" 3 eyed snail") representing the bifurcation of the PSA as it traverses the floor of the middle cranial fossa to give rise the middle meningeal artery (white arrows). Labyrinthine (black arrows) and tympanic (white arrowheads) segments of the facial nerve represent usually seen "2 eyes of the snail." Right ear $(C)$ and left ear $(D)$ axial CT images in the same patients demonstrate duplication of the anterior segment of the tympanic facial nerve canal (white arrows). The labyrinthine segment (black arrows), tympanic segment (white arrowheads), and PSA canal intersect to form an "N" on the left $(D)$ and a reverse "N" on the right (C). Geniculate ganglion is seen anteromedially (black arrowheads). TT = tensor tympani.
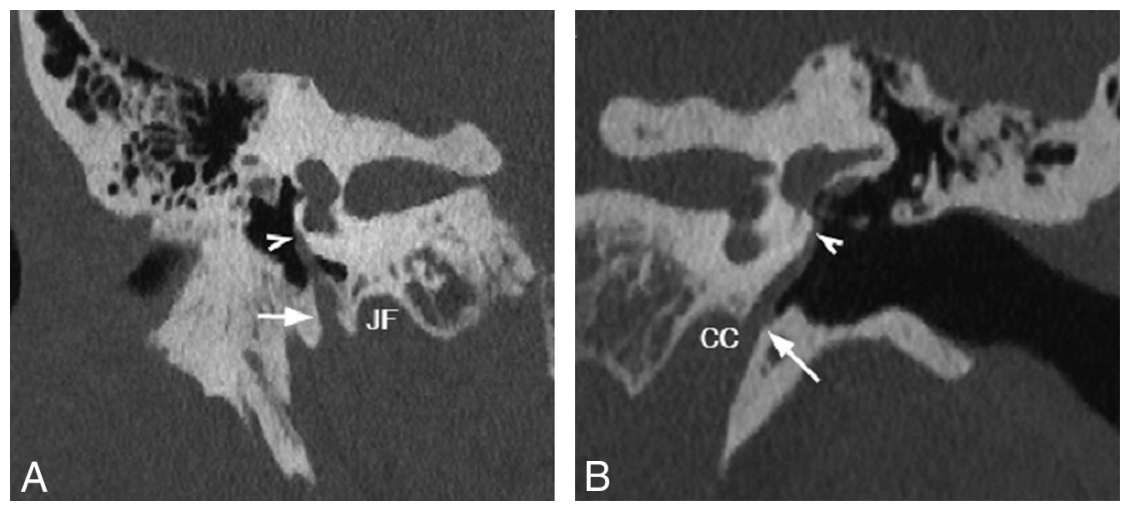

FIG 6. Coronal oblique CT reconstructions demonstrate PSA coursing over the lateral surface of the cochlear promontory (string sign). Right PSA $(A)$ arises from the inferior tympanic canaliculus (arrow), and left PSA (B) takes its origin from the carotid canal via caroticotympanic canaliculus (arrow), both traversing cephalad over the cochlear promontory (arrowheads). CC = carotid canal; JF = jugular foramen.

\section{Imaging Signs: "Three-Eyed Snail" Sign}

As previously discussed, an osseous canal sometimes separates the facial nerve and the stapedial artery. This results in a characteristic appearance on coronal imaging planes, predictably altering the common anatomic radiologic landmark known as the "snail eyes." The usual " 2 eyes" correspond to the labyrinthine and tympanic segments of the facial nerve in cross-section; the snail shell is implied by the cochlear spiral. In cases of PSA with a duplicated facial nerve canal, a rounded soft tissue mass lateral to the tympanic segment of the facial nerve is seen in the coronal plane, giving the impression of a "third eye" (Fig $5 A,-B$ ). This sign was observed in 6 of 10 PSA cases (60\%) in our series.

\section{Imaging Signs: “N” Sign}

As an axial corollary to the "3-eyed snail" sign, PSA can have a characteristic appearance at the level of the geniculate ganglion. Here, the distal tympanic segment of the PSA appears as a tubular soft tissue attenuation coursing lateral to tympanic segment of the facial canal. This attenuation adds an additional limb to the classic upside down " $V$ " shape of the facial nerve canal at the level of the geniculate ganglion, transforming the "V" into an "N" if on the left and reverse
" $\mathrm{N}$ " if on the right side (Fig $5 C,-D$ ). Expectedly, this sign was also observed in 6 of 10 PSA cases (60\%) in our series.

\section{Imaging Signs: "String" Sign}

In both sagittal and coronal planes, the vertically oriented proximal PSA can be observed as a thin linear soft tissue attenuation coursing over the cochlear promontory after emerging from its bony channel (either the inferior tympanic or caroticotympanic canaliculi), referred to as the "string sign" (Fig 6). The trajectory of the "string" varies by subtype, with the pharyngostapedial artery (from the ITA) coursing along the posterior surface just anterior to the round window niche and the hyoidostapedial artery (from the CTA) taking a more anterior course (Fig 7). This sign was observed in all 10 PSA cases (100\%) in our series.

\section{Imaging Signs: “Ringer" Sign}

The PSA may be observed in cross-section as a discrete dot within the obturator foramen, typically marginating the inner aspect of the stapedial anterior crus. In this view, it is reminiscent of a horseshoe encircling a stake, a configuration known as a "ringer" in the parlance of the popular lawn game (Fig 8). In 8 of 10 PSA cases (80\%) in our series, this imaging finding could be readily identified.

\section{CLINICAL IMPLICATIONS}

Although most patients with a PSA are asymptomatic, a variety of symptoms have been reported, most commonly CHL and pulsatile tinnitus. These 2 symptoms were corroborated by the current series. CHL may result from ossicular dampening caused by the traversing PSA or a concomitant malformation of the stapes suprastructure, such as the one in the current series with an absent anterior stapedial crus. None of the patients in the current series had clinical findings suggestive of a footplate fixation. The cause of pulsatile tinnitus is best explained by sound transmission through the cochlear promontory to the cochlea and potentially 

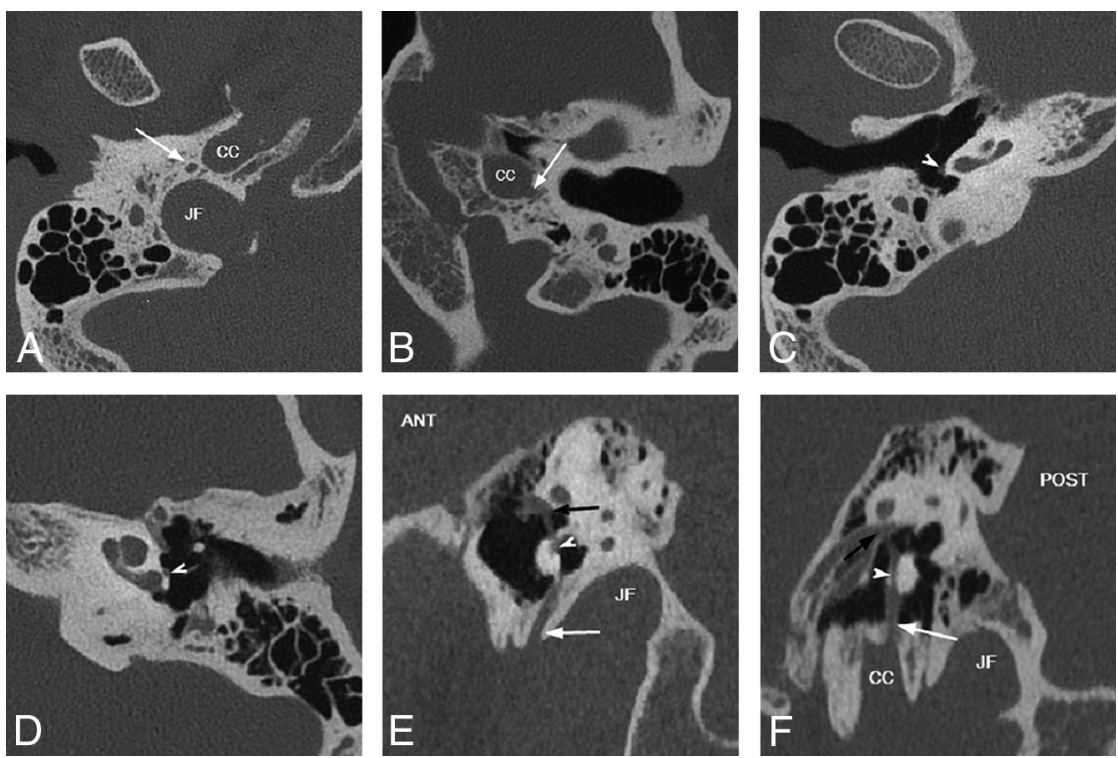

FIG 7. Variable origin of the PSA. Axial $(A-D)$ and sagittal oblique $(E$ and $F) C T$ reconstructions. In $A$, $C$, and E, PSA arises from the ITC posterolateral to the carotid canal (CC) and anterior to the jugular foramen (IF), (white arrows). In B, D, and F, PSA arises directly from CC via CTC (white arrows). Note the posterior position of the PSA on the cochlear promontory with ITC origin versus the anterior position with CTC origin (white arrowheads), best seen on sagittal reconstructions, $E$ and F, PSA traverses oval window niche to enter tympanic segment of the facial nerve canal (black arrows). $\mathrm{ANT}=$ anterior; $\mathrm{POST}=$ posterior

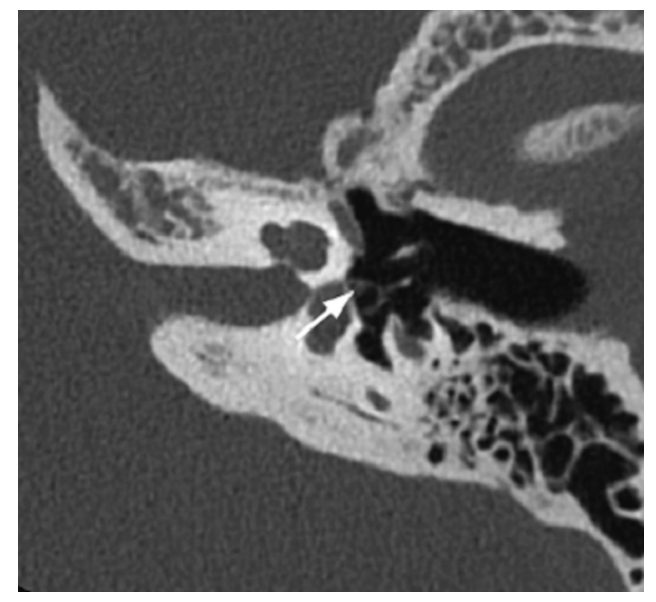

FIG 8. PSA courses through the obturator foramen of the stapes. Oblique axial CT reconstruction demonstrates cross-section of the artery along the inner margin of the anterior crus of the stapes (arrow) resembling a horseshoe on a stake (ringer sign).

by pulsations transmission via the stapes, where the PSA may abut stapedial crura. The symptom of pulsatile tinnitus may be more pronounced in patients with concomitant CHL.

The presence of a PSA historically has been a cause for perioperative concern, primarily because of bleeding risk and cerebral ischemia. ${ }^{33,34}$ The primary risk of PSA transection is facial nerve palsy resulting from nerve injury or ischemia. In the current series, 1 PSA was successfully transected, in line with recent studies demonstrating surgical feasibility without significant complications in most patients with PSA. However, as is clear from the other 2 surgically aborted cases in our series, PSA can potentially pose a concern for a surgeon. Current strategies for symptomatic PSAs include transection of the vessel, particularly for pulsatile tinnitus, and/or ossicular chain reconstruction for CHL. ${ }^{1,35,36}$

PSA has been reported in association with numerous congenital anomalies and conditions, including trisomies 13,15 , and 21, Paget disease, otosclerosis, thalidomide deformities, anencephaly, congenital immunodeficiency, and neurofibromatosis. ${ }^{10,15}$ The current series also documents associated congenital anomalies in 3 of 9 patients, including ipsilateral congenital cholesteatoma, ipsilateral congenital aerodigestive venolymphatic malformation, and chromosome $3 \mathrm{q}$ duplication or trisomy.

To date, this is the largest published series of CT findings in PSA. This imaging review highlights several pathognomonic CT signs and morphologic variations, which can give radiologists confidence identifying this vessel. Additionally, given significant association with congenital anomalies, the presence of a PSA on CT should prompt further investigation for potential concurrent imaging abnormalities. Although most of the described signs proving direct evidence of PSA are largely only appreciable on high-resolution temporal bone CT on workstations with reformat capabilities, absence of the foramen spinosum on routine head CTs may give a clue to a variant arterial anatomy, and further investigation could be suggested in an appropriate clinical setting. Additionally, because virtually all routine head CTs nowadays are acquired helically, source images at 0.625 or $0.75 \mathrm{~mm}$ might permit resolution high enough to visualize PSA above the absent foramen spinosum.

\section{CONCLUSIONS}

PSA is probably best understood as a spectrum of anomalous embryonic vessels that may persist postnatally in various forms. When encountered on CT, systematic evaluation of its proximal and distal course may help clarify its embryonic origin. As discussed, PSA may be both a structural cause for the patient's symptoms and an important factor for surgical planning and is therefore a variant worthy of consideration and comment when identified.

\section{REFERENCES}

1. Govaerts PJ, Marquet TF, Cremers WRJ, et al. Persistent stapedial artery: does it prevent successful surgery? Ann Otol Rhinol Laryngol 1993;102:724-28 CrossRef Medline

2. Moreano EH, Paparella MM, Zelterman D, et al. Prevalence of facial canal dehiscence and of persistent stapedial artery in the human middle ear: a report of 1000 temporal bones. Laryngoscope 1994;104:30920 CrossRef Medline

AJNR Am J Neuroradiol 42:160-66 Jan $2021 \quad$ www.ajnr.org 
3. Hyrtl J. Neue beobachtungen aus dem gebiete der menschlichen und vergleichenden anatomie. Med Jahrb d Oesterreich Staates 1836;10:457-66

4. House HP, Patterson ME. Persistent stapedial artery: report of two cases. Trans Am Acad Ophthalmol Otolaryngol 1964;68:644-46 Medline

5. Mahajan AC, Chaudhary N, Mishra M. Persistent stapedial artery: an otomicroscopic finding. Int J Anat Var 2018;11:2013-14

6. Pahor AL, Hussain SS. Persistent stapedial artery. J Laryngol Otol 1992;106:254-57 CrossRef Medline

7. Diamond MK. Homologies of the stapedial artery in humans, with a reconstruction of the primitive stapedial artery configuration of euprimates. Am J Phys Anthropol 1991;84:433-62 CrossRef Medline

8. Diamond MK. Unusual example of a persistent stapedial artery in a human. Anat Rec 1987;218:345-54 CrossRef Medline

9. Kelemen G. Arteria stapedia, in bilateral persistence. AMA Arch Otolaryngol 1958;67:668-77 CrossRef Medline

10. Marion M, Hinojosa R, Khan AA. Persistence of the stapedial artery: a histopathologic study. Otolaryngol Head Neck Surg 1985;93:298-312 CrossRef Medline

11. Guinto J, Garrabrant EC, Radcliffe WB. Radiology of the persistent stapedial artery. Radiology 1972;105:365-69 CrossRef Medline

12. Baltsavias G, Kumar R, Valavanis A. The pharyngo-tympano-stapedial variant of the middle meningeal artery. A case report. Interv Neuroradiol 2012;18:255-58 CrossRef Medline

13. Silbergleit R, Quint DJ, Mehta BA, et al. The persistent stapedial artery. AJNR Am J Neuroradiol 2000;21:572-77 Medline

14. Lefournier V, Vasdev A, Bessou P, et al. A persistent pharyngohyostapedial artery: embryologic implications. AJNR Am J Neuroradiol 1999;20:271-74 Medline

15. Thiers FA, Sakai O, Poe DS, Curtin HD. Persistent stapedial artery: CT findings. AJNR Am J Neuroradiol 2000;21:1551-54 Medline

16. Dimmick SJ, Faulder KC. Normal variants of the cerebral circulation at multidetector CT angiography. Radiographics 2009;29:102743 CrossRef Medline

17. Nica MI, Cosnard G. Persistent stapedial artery: a congenital anomaly to know. JBR-BTR 2013;96:22-24 CrossRef Medline

18. Jehl J, Jeunet L, Berraiah $M$, et al. Bilateral persistent pharyngo-stapedial arteries revealed during evaluation of a carotid-cavernous fistula. 3 Tesla MR angiographic aspects. Interv Neuroradiol 2006;12:327-34 CrossRef Medline

19. Hatipoglu HG, Cetin MA, Yuksel E, et al. A case of a coexisting aberrant internal carotid artery and persistent stapedial artery: the role of MR angiography in the diagnosis. Ear Nose Throat J 2011;90: E17-20 CrossRef Medline

20. Congdon E. Transformation of the aortic-arch system during the development of the human embryo. Contrib Embryol 1922;14
21. Padget $\mathrm{D}$. The development of the cranial arteries in the human embryo. Contrib Embryol 1948;32:205-61

22. Altmann F. Anomalies of the internal carotid artery and its branches; their embryological and comparative anatomical significance. Report of a new case of persistent stapedial artery in man. Laryngoscope 1947;57:313-39 Medline

23. Steffen TN. Vascular anomalies of the middle ear. Laryngoscope 1968;78:171-97 CrossRef Medline

24. Strickland EM, Hanson JR, Anson BJ. Branchial sources of auditory ossicles in man. I. Literature. Arch Otolaryngol 1962;76:10022 CrossRef Medline

25. Rodesch G, Choi I, Lasjaunias P. Complete persistence of the hyoido-stapedial artery in man. Surg Radiology Anat 1991;13:63-65 CrossRef Medline

26. Andreo JC, Caldas Navarro JA, Toledo Filho JL, et al. Caroticotympanic artery: anatomically a normal branch or a variation of the internal carotid artery? Cells Tissues Organs (Print) 2000;166:319-22 CrossRef Medline

27. Quisling RG, Rhoton AL. Intrapetrous carotid artery branches: radioanatomic analysis. Radiology 1979;131:133-36 CrossRef Medline

28. Hitier $M$, Zhang $M$, Labrousse $M$, et al. Persistent stapedial arteries in human: from phylogeny to surgical consequences. Surg Radiology Anat 2013;35:883-91 CrossRef Medline

29. Moret J, Delvert JC, Bretonneau CH, et al. Vascularization of the ear: normal-variations-glomus tumors. J Neuroradiol 1982;9:209-60 Medline

30. Nager GT, Nager M. The arteries of the human middle ear, with particular regard to the blood supply of the auditory ossicles. Ann Otol Rhinol Laryngol 1953;62:923-49 CrossRef Medline

31. Alexander G. Ein fall von persistenz der arteria stapedia beim menschen. Monatsschr Ohrenheilkd Laryngorhinol 1899;33:273-76

32. Royle G, Motson R. An anomalous origin of the middle meningeal artery. J Neurol Neurosurg Psychiatry 1973;36:874-76 CrossRef Medline

33. Wardrop P, Kerr AI, Moussa SA. Persistent stapedial artery preventing successful cochlear implantation: a case report. Ann Otol Rhinol Laryngol Suppl 1995;166:443-45 Medline

34. Hogg ID, Stephens CB, Arnold GE. Theoretical anomalies of the stapedial artery. Ann Otol Rhinol Laryngol 1972;81:860-70 CrossRef Medline

35. Goderie TPM, Alkhateeb WHF, Smit CF, et al. Surgical management of a persistent stapedial artery: a review. Otol Neurotol 2017;38:78891 CrossRef Medline

36. Breheret R, Bizon A, Tanguy JY, et al. Persistent stapedial artery with otosclerosis. Ann Otolaryngol Chir Cervicofac 2009;126:259-63 CrossRef Medline 